\title{
Experimental modal analysis of a linear reciprocating tribometer for maximum reciprocating frequency
}

\author{
Harish Thetanikkal Viswanathan*, Prem Kumar John and Rajeev Vamadevan Rajalekshmi \\ Department of Mechanical Engineering, College of Engineering, Trivandrum (CET), Thiruvananthapuram, 695 016, India \\ * Corresponding Author: harishtv06@gmail.com
}

Submitted :07/05/2020

Revised :05/07/2021

Accepted : 27/09/2021

\begin{abstract}
This work demonstrates the estimation of critical reciprocating frequency of a fabricated linear pin-onreciprocating plate tribometer by modal analysis. An experimental investigation by impact testing and numerical analysis using ANSYS Work bench 14 were performed to extract the modal parameters of individual subsystems. The authors could not find reported literature on the estimation of critical reciprocating frequency of pin-onreciprocating plate tribometer. The authors developed a pin-on-reciprocating plate tribometer that can simulate friction and wear under reciprocating sliding conditions for stroke lengths up to $150 \mathrm{~mm}$. The developed pin-onreciprocating plate tribometer had a loading subsystem, transmission subsystem, and measurement subsystem. From experimental and numerical estimation of modal parameters, transmission subsystem was found to have the lowest modal frequency of $18 \mathrm{~Hz}$. Maximum frequency of reciprocation was then fixed at $30 \%$ of the lowest modal frequency of $18 \mathrm{~Hz}$, that is, $5 \mathrm{~Hz}$. Confirmatory friction tests were then conducted on the tribometer and found that the identification of maximum frictional force was difficult when the reciprocating frequency of plate of tribometer exceeded $4 \mathrm{~Hz}$ due to vibrations in measuring system and agreed with the reported literature. This work addresses the need of methodology for establishing critical reciprocating frequency of tribometer. This paper elaborates the modal analysis of a fabricated linear reciprocating tribometer. Resonance of subsystems in reciprocating tribometer affects experimental estimate of coefficient of friction $(\mathrm{CoF})$. Subsystems have their own individual modal frequencies. Hence, modal analysis of all subsystems becomes obligatory. Tribometer developed for this study can simulate reciprocating friction and wear for stroke lengths up to $150 \mathrm{~mm}$. Experimental and numerical analyses were utilized to identify modal frequency of individual subsystems. Tests identified that transmission subsystem had the lowest modal frequency of $18 \mathrm{~Hz}$. The maximum frequency of reciprocation was then fixed at $4 \mathrm{~Hz}$. This is $25 \%$ of the lowest modal frequency of $18 \mathrm{~Hz}$ as delineated in the literature. Confirmatory friction tests were then conducted on the tribometer. Resolving maximum frictional force along the stroke length was impossible over $4 \mathrm{~Hz}$ of reciprocating frequency. This is $25 \%$ of the lowest modal frequency of structure and agreed with the reported literature. The authors sincerely hope that the methodology used in this paper will guide fellow researchers for modal analysis of reciprocating tribometer.
\end{abstract}

Keywords: Reciprocating tribometer; Modal analysis; System response; Reciprocating frequency. 


\section{INTRODUCTION}

Tribological properties can be estimated only by experimentation (Blau, 1994, Bharat, 2000, Stachowiak and Batchelor, 2004). Model tests and laboratory tests with specimens taken from the actual components are extensively used for tribological evaluation. In the laboratory tests, the experimenter has full control of the parameters. G133 standard of American Society for Testing and Materials (G133-02, 2002) evaluates wear and friction under reciprocating sliding condition. Pin-on-reciprocating plate tribometers were used to measure friction by direct linear force measurement as per the ASTM G-133 standard. In tribometers with reciprocating motion, dry sliding friction imparts large forces into the structure of tribometers. Assessing the reliability of measured friction response by the tribometer structure is important to yield acceptable results, especially in dry sliding wear. This is necessary to confirm test parameter ranges, so that the validity of obtained results is higher. Amplitudes and duration of frictional force can fluctuate over time. The design of tribometer should enable the identification of these variations and, at the same time, distinguish the variations from tribometer structure induced fluctuations. Kinetic friction or dynamic friction is measured with tribometers. The validity of friction coefficient is limited by the details of the conditions used to obtain them (Blau, 2001). The covariant attributes like general trends, the extent of certain events, and minor duration fluctuations in amplitudes of coefficient of friction had been taken care of during the wear tests. By recording and monitoring, the $\mathrm{CoF}$ real time information of wear phenomenon can be assessed (Blau, 1989). According to Plint (2011), frictional force in tribological experiment is dynamic and perturbed by vibrations in the system. Increased reciprocating frequency reduced the apparent mean frictional force since information content of the signal decreased with increased reciprocating frequency. Transition of frictional forces from static to dynamic induced the plucking effect, which in turn induced vibration and was due to the fixed signal bandwidth of tribometers. Hence, it was recommended to limit the reciprocating frequency in tribo-tests to $30 \%$ of the resonant frequency of tribometer. Frictional force measurement should be taken from $25 \%$ and above of stroke length (Plint, 2011). It is evident from the literature that the estimation of resonant frequency of tribometer is unavoidable for reliable frictional force measurement using reciprocating tribometer. However, limited studies are available on the estimation of maximum reciprocating frequency of a tribometer with reciprocating sliding contact (Ramalho and Celis, 2003).

Demonstration of modal parameter estimation by experiments and numerical analysis can help improve the reliability of $\mathrm{CoF}$ estimation of researchers. This paper demonstrates the estimation of modal parameters of a pin-onreciprocating plate tribometer. Experimental modal frequencies can be obtained by exciting a structure and measuring its operating deflection shape in every possible degrees of freedom (DoF) (Schwarz and Richardson, 1999). Real time estimation of frequency response function (FRF) is possible with MEscopeVESTM software. The authors as part of their sponsored research project developed a pin-on-reciprocating plate tribometer. To fix the ranges of test parameters, the authors performed modal analysis of the developed tribometer. Triaxial accelerometer with MEScope software was utilized to ascertain the lowest modal frequency of each subsystem. The experimentally estimated modal parameters were then compared with numerically estimated frequency using the Ansys Work Bench 14 software. Transmission subsystem had the lowest modal frequency of $18 \mathrm{~Hz}$. It was reported (Plint, 2011) that maximum allowable frequency of reciprocation should be limited to $30 \%$ of lowest modal frequency. Hence, $30 \%$ of $18 \mathrm{~Hz}$, that is, $5 \mathrm{~Hz}$, was taken as maximum reciprocating frequency of plate in the developed tribometer. Later, confirmatory tests were conducted under loads of $30 \mathrm{~N}, 60 \mathrm{~N}$, and $90 \mathrm{~N}$ at reciprocating frequencies of $1 \mathrm{~Hz}-6 \mathrm{~Hz}$. Isolation of frictional force peaks was difficult when the frequency of reciprocation was over $4 \mathrm{~Hz}$ or $25 \%$ of the maximum modal frequency. Hence, the maximum frequency of reciprocation of a pin-on-reciprocating plate tribometer should never exceed $25 \%$ of the minimum modal frequency. 


\section{EXPERIMENTAL SETUP}

\subsection{Fabricated Reciprocating Tribometer}

Details of fabricated pin-on-reciprocating plate tribometer are given in Fig. 1 and Fig. 2. Tribometer consisted of (1) loading subsystem, (2) transmission subsystem, and (3) measuring subsystem.

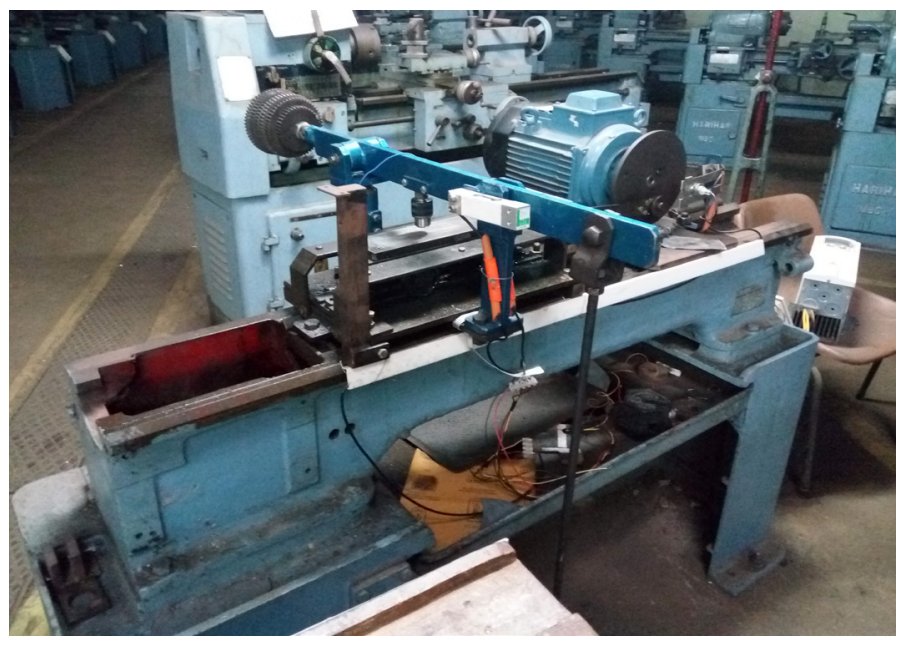

Figure 1. Developed tribometer

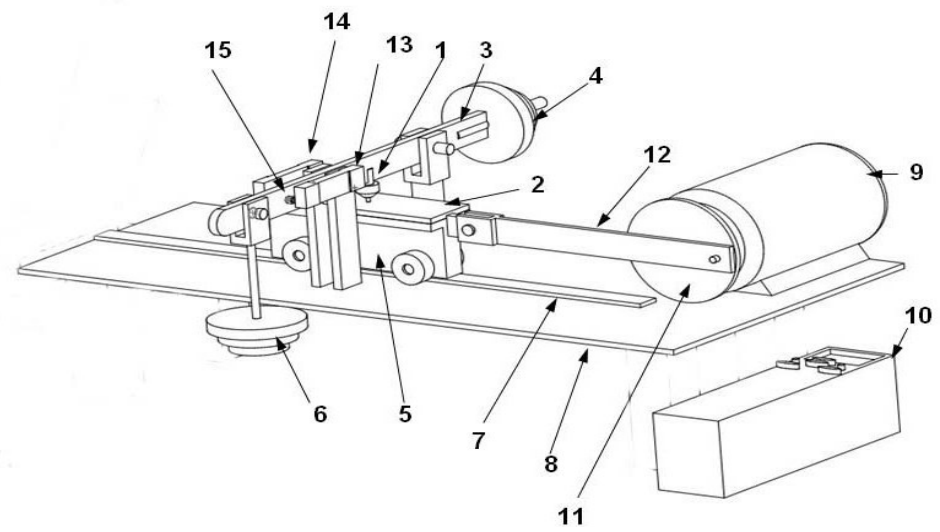

Figure 2. Pictorial view of the developed reciprocating plate tribometer. (1) Specimen holder.

(2) Counter surface. (3) Loading arm. (4) Counterweights. (5) Trolley. (6) Normal load hanger with weights.

(7) Trolley guide. (8) Tabletop. (9) $2.2 \mathrm{~kW}$ Electric Motor. (10) VFD Drive. (11) Crank disc.

(12) Connecting rod. (13) \& (14) Load cells. (15) Bolts for adjusting clearance.

\subsubsection{Loading Subsystem}

The Fig. 3 shows the components of the loading subsystem. This consisted of a drill chuck of $12 \mathrm{~mm}$ capacity used as specimen holder (1). The counter surface (2) was EN 32 steel plate of $10 \mathrm{~mm}$ thickness fixed on top of trolley 
(5). The specimen holder fixed on the loading arm (3). The loading arm pivoted on a point (18) and was able to swing about the loading arm support pillar (19) to transmit the frictional force. The lateral frictional force transferred to the load cells through bolts for adjusting clearance.

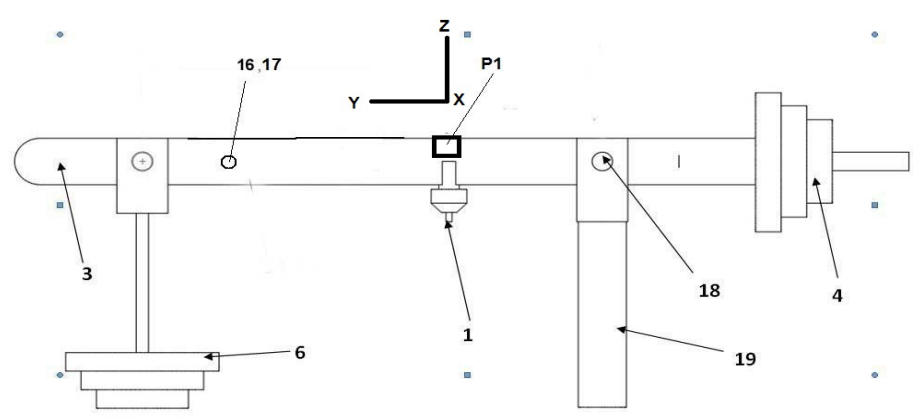

Figure 3. The loading subsystem of the tribometer. (1) Specimen holder. (3) Loading arm. (4) Counterweights. (6) Normal load hanger with weights. (16) and (17) Bolts for adjusting clearance. (18) Loading arm pivot point. (19) Loading arm pillar support. (P1) Location of accelerometer for modal tests.

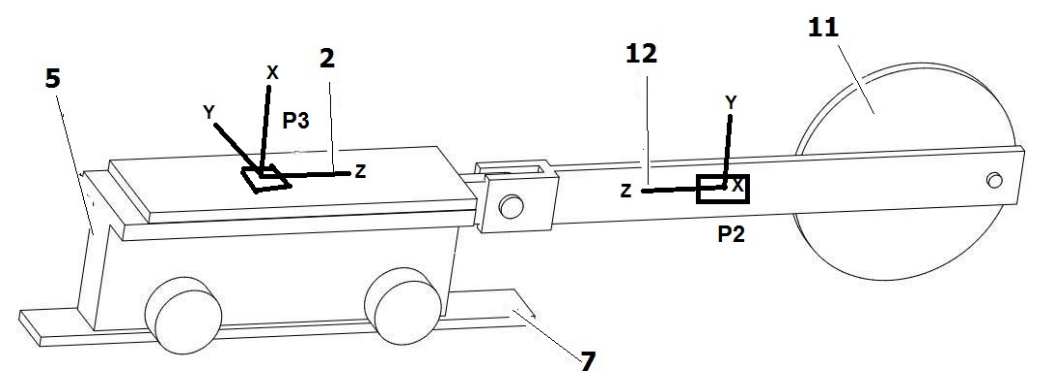

Figure 4. The transmission subsystem. (2) Counter surface. (5) Trolley. (7) Trolley guide. (11) Crank disc. (12) Connecting rod (P2 \& P3) Location of Accelerometer for modal tests.

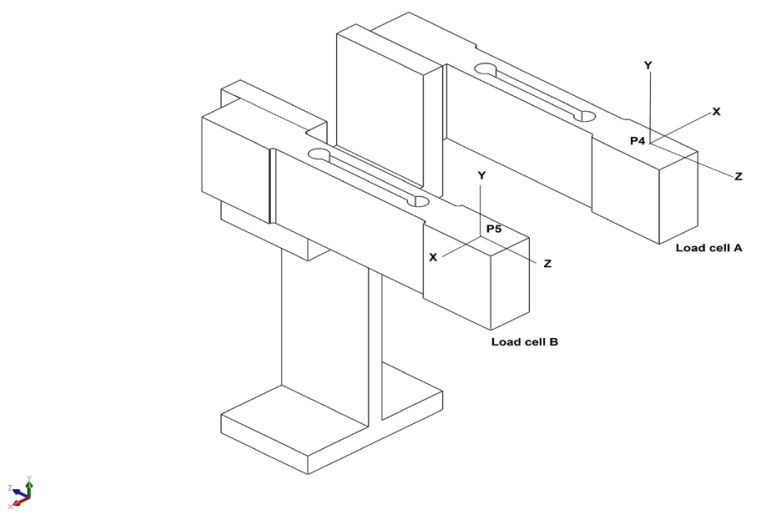

Figure 5. The measurement subsystem. (13) Load cell A and (14) load cell B (P4 and P5) Location of accelerometer for modal tests. 


\subsubsection{Transmission Subsystem}

The transmission system of the tribometer consisted of (9) an AC motor (ABB make, model M2BA 112 M-6). The rotational speed of the motor controlled by a VFD drive (ABB make, model ACS550-01-05A4-4) (10). The rotary motion converted to oscillatory motion by a crank disc (11). Motion transmitted to the trolley (5) through a connecting rod (12). The stroke length of reciprocation of trolley was equal to twice the radial distance of the point on which connecting rod end fixed on the disc. The trolley movement on the tabletop (8) was aligned by a trolley guide (7) on the table. The crank disc rotated at the set RPM and the trolley reciprocated for the set stroke length at the desired average velocity. The details of transmission system were provided in Fig. 4.

\subsubsection{Measuring subsystem}

The frictional forces were measured using two load cells as in Fig. 5. Two single point load cells with Type C3 class accuracy were used. The maximum capacity of the load cells was 20 Kilograms, and the excitation voltage was $10 \mathrm{~V}$ at the rate $2 \mathrm{mV} / \mathrm{V}$. The clearance between the load cells and frictional force transfer bolts on the loading arm was maintained by adjusting bolts $(16,17)$ on both sides of the loading arm. The output of the load cell after amplification was sent to the National Instruments made Data Acquisition System (NI-cDAQ 9178 with NI USB9234, 4-Channel, 5 V, 24-Bit Software-Selectable IEPE and AC/DC Analog Input Module for recording on the PC). The load cells were calibrated using the calibration equation, and the voltage was converted to frictional force

\subsection{Sensor and Instrumentation}

An impact hammer was used to excite the tribometer structure to evaluate dynamic response of the tribometer parts and their modal frequencies. The impact hammer used was of PCB Electronics (Model 086C03, $2.25 \mathrm{mV} / \mathrm{N}$ ). Tri-axial accelerometer (Make PCB Electronics; Model 356A16) was used to record vibration response on tribometer at specific points on every subsystem. The signals were transferred to the computer using the NI Data Acquisition System (NI-cDAQ 9178 with NI USB-9234, 4-Channel, 5 V, 24-Bit Software-Selectable IEPE and AC/DC Analog Input Module). The data were collected at the rate of 5000 samples per second, so that maximum resolvable response frequency is $2500 \mathrm{~Hz}$. MEscopeVESTM software was used for onsite FRF analysis.

\section{EXPERIMENTAL DETERMINATION OF MODAL FREQUENCIES}

For all the measurements, the sampling frequency was set to 5000 samples per second considering the Nyquist sampling frequency. Fig. 3 shows the loading arm and the excitation point. To get better structure response, the loading arm was excited with the impact hammer without any loads. Dynamic response was measured by fixing the accelerometer at position "P1." This point represents the maximum excitation point of the loading arm when tribotesting was carried out. 


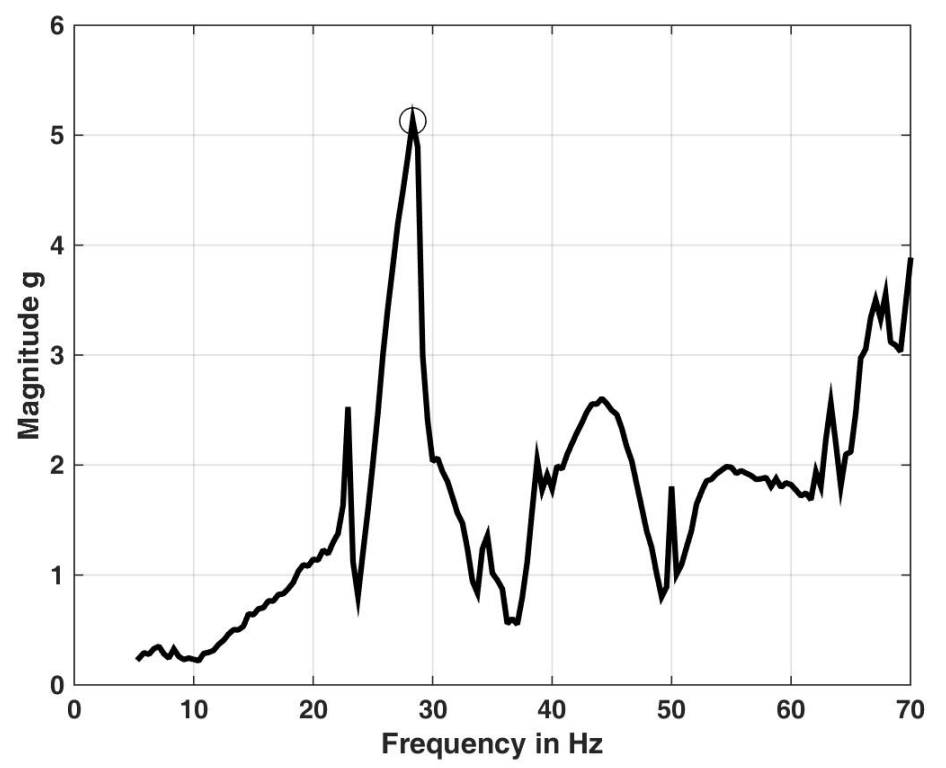

Figure 6. FRF of real part of the loading arm.

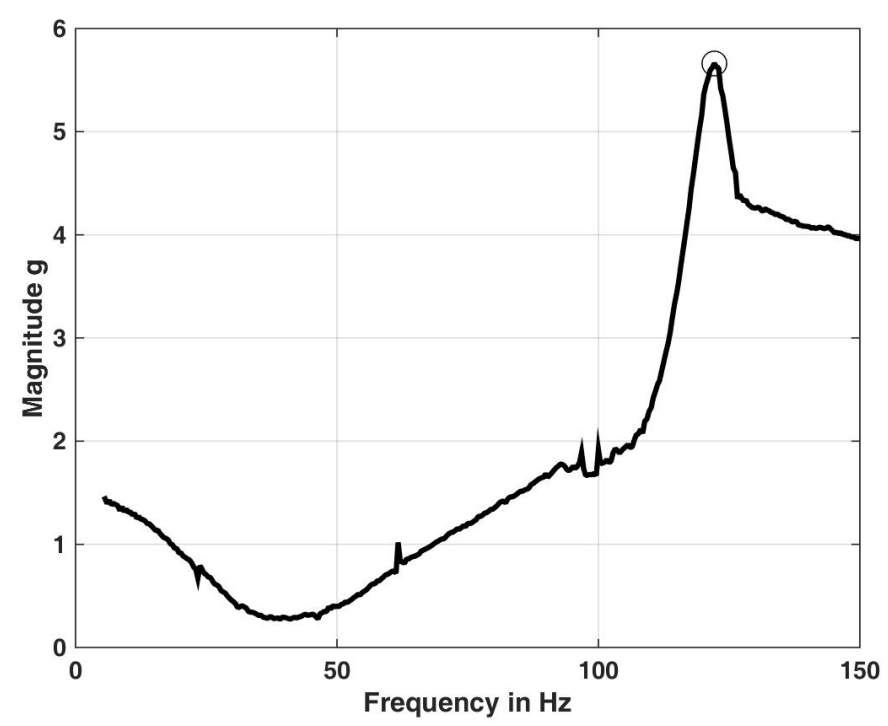

Figure 7. FRF of real part of the connecting rod.

Fig. 6 gives the FRF of the loading arm subsystem from MEscopeVESTM. The peak was obtained at $28 \mathrm{~Hz}$ and was taken as the lowest modal frequency of the loading subsystem. Excitation and measurement of response of transmission subsystem were obtained from multiple points recorded in this subsystem. Fig. 4 shows connecting rod with all attachments. The connecting rod was maintained in the horizontal position. Dynamic response was measured by fixing the accelerometer at position "P2." Since this location represents the maximum deflection point if excited, and the FRF was obtained as shown in Fig. 7, the minimum modal frequency of the connecting rod was $128 \mathrm{~Hz}$. 
The FRF of the trolley with all attachments is provided in Fig. 8. Dynamic response measured was by fixing the accelerometer at position "P3." Since this point represents the maximum deflection point, the minimum modal frequency of the trolley was $18 \mathrm{~Hz}$. Excitation and recording of the vibration response of measurement subsystem were carried out by fixing the accelerometer at position "P4" for load cell A and at "P5" for load cell B as in Fig. 5. The minimum resonance frequency of load cell A was $97 \mathrm{~Hz}$, and for load cell B, it was $98 \mathrm{~Hz}$ as given in Fig. 9 and Fig. 10, respectively.

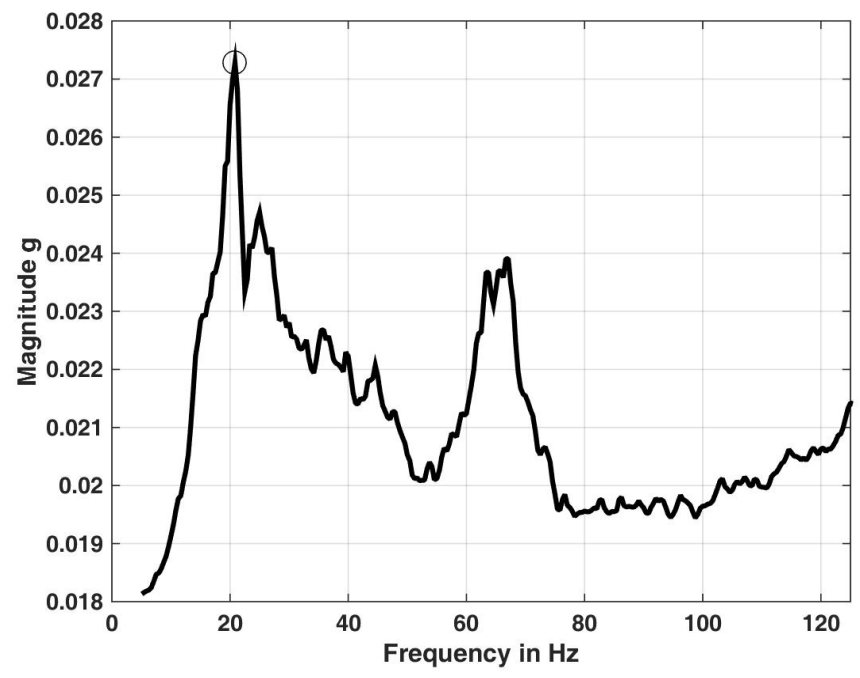

Figure 8. FRF of real part of the trolley.

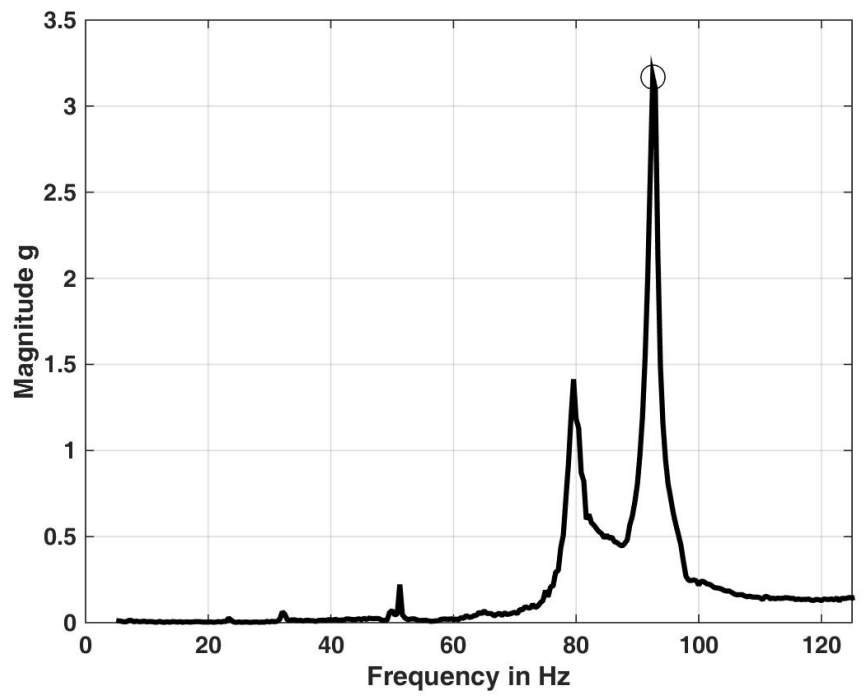

Figure 9. FRF of real part of the load cell A. 


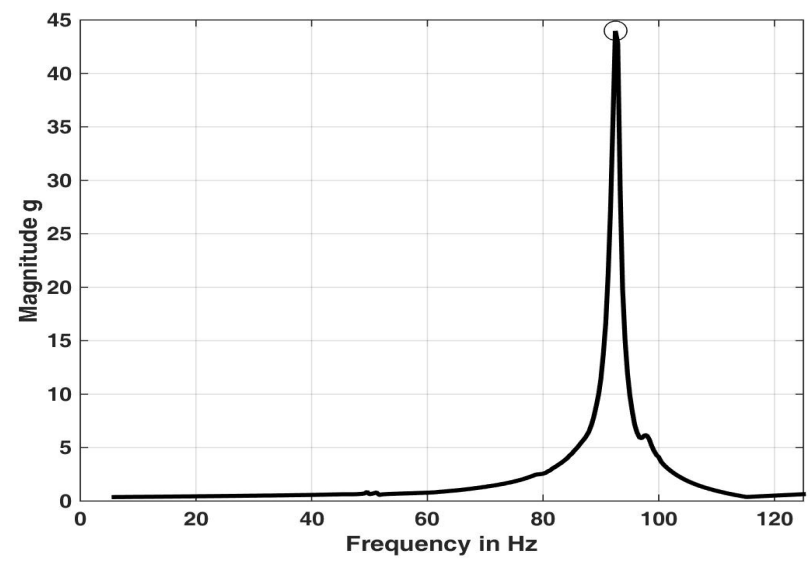

Figure 10. FRF of real part of the load cell B.

\subsection{Frequency Response Function}

The details of FRF estimation and its significance are explained in Brandt (2011). Black box concept of system theory was used to relate the output of the system to a known input. In the time domain, the input signal is denoted by $\mathrm{x}(\mathrm{t})$ and the output signal by $\mathrm{y}(\mathrm{t})$. The transfer function is $\mathrm{H}(\mathrm{s})$, which is the ratio $\mathrm{Y}(\mathrm{s})=\mathrm{X}(\mathrm{s})$, where $\mathrm{Y}(\mathrm{s})$ and $\mathrm{X}(\mathrm{s})$ are the Laplace transform of the output and input signals. The impulse response of the system $h(t)$ is obtained by taking the inverse Laplace transform of transfer function $\mathrm{H}(\mathrm{s})$. The frequency response function (FRF) H(f) was estimated from measurements of forces and acceleration signals.

$$
H(f)=\frac{Y(f)}{X(f)}
$$

Ref. [Brandt(2011a)] where Y (f) and X(f) are the Fourier transform of output and input signals. The procedure for calculating the FRF involves measuring the input and output signals, $x(t)$ and $y(t)$, respectively, in the time domain. These are transformed into the frequency domain as X(f) and $\mathrm{Y}(\mathrm{f})$, respectively. Force window was selected for the impact force from impact hammer and exponential windowing for the accelerometer responses. The purpose of the force window was to improve the signal-to-noise ratio of the measured input by eliminating the noise on the signal following the duration of the impact (Unnikrishnan et al., 2017). Exponential window was used for accelerometer responses to attenuate the noise on the measured output after the response has decayed due to system damping. All these were calculated by the MEscopeVESTM software.

\section{NUMERICAL MODAL ANALYSISS}

The structural members of the developed tribometer were made from mild steel. The loading never exceeded elastic limit. Hence, all parts can be taken as linear elastic and hence obey Hooke's Law. For numerical analysis, a dynamic three-dimensional spring mass system was assumed. The detailed theory of numerical modal analysis can be found in the paper by Lee et al. (Lee and Lee, 2012) and is quoted here. The generalized equation of motion is given as follows:

$[M]\{\ddot{u}\}+[C]\{\dot{u}\}+[K]\{u\}=[F]$ 
where $[\mathrm{M}]$ is the mass matrix, and $\{\ddot{u}\}$ and $\{\dot{u}\}$ are the first and second time derivatives of displacement $\mathrm{u}$, that is, the acceleration and velocity matrices. $[\mathrm{C}]$ is the damping, and $[\mathrm{K}]$ is the stiffness matrices, respectively. $[\mathrm{F}]$ is the force vector. Modal analysis was used for natural frequency and mode shape determination. For vibrational modal analysis, damping was generally ignored.

$$
[M]\{\ddot{u}\}+[K]\{u\}=0
$$

The equation of motion for an undamped system, expressed in matrix notation, is as in Equation. 3. The free vibrations in a linear system will be harmonic and will be as follows:

$$
\{u\}=\{\varphi\}_{i} \operatorname{Sin}(\omega t)
$$

Thus, Eq. 3 can be rewritten as

$$
\left(-\omega^{2}[M]+[K]\right)\{\varphi\}_{i=\{0\}}
$$

This equality is satisfied if either $\{\varphi\}_{i}=0$ or if the determinant of $\left(-\omega^{2}[M]+[K]\right)=0$. The first option is trivial and therefore is not of interest. The second gives the following solution:

$$
\left|[K]-\omega^{2}[M]\right|=\{0\}
$$

This is an eigen value problem, which may be solved for up to $\mathrm{n}$ values of $\omega^{2}$ and $\mathrm{n}$ eigenvectors $\{\varphi\}_{i}$ which satisfy Eq. 4, where $\mathrm{n}$ is the number of DOFs. The eigenvalue and eigenvector extraction techniques are used in the Block Lanczos method. Rather than outputting the natural circular frequencies $\omega$, the natural frequencies $\left(f_{n}\right)$ are output as

$$
f_{n=} \omega / 2 \pi
$$

where $f_{n}$ is the nth natural frequency. Normalization of each eigenvector $\{\varphi\}_{i}$ to the mass matrix is performed according to

$$
\{\varphi\}_{i}^{T}[M]\{\varphi\}_{i}=0
$$

In the normalization, $\{u\}_{i}$ is normalized, such that its largest component is 1.0 (unity). The numerical analysis can be carried out using the ANSYS Work Bench 14 software. Each subsystem of the tribometer was analyzed, separately. The elements used were SOLID186 and modes of vibration and were modeled. The material for the structure was mild steel and was selected from the library. The material for the load cells was aluminum and was selected from the ANSYS library. Those components of the subsystem had relative motion and were modeled accordingly. Some of the components of the subsystems of the tribometer were fixed firmly on the base plate, and in the modeling, those surfaces were made fixed. 


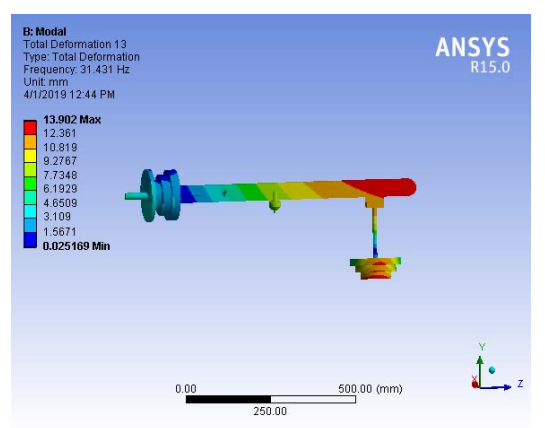

Figure 11. Modal frequency $(31.431 \mathrm{~Hz})$ and mode shape of arm.

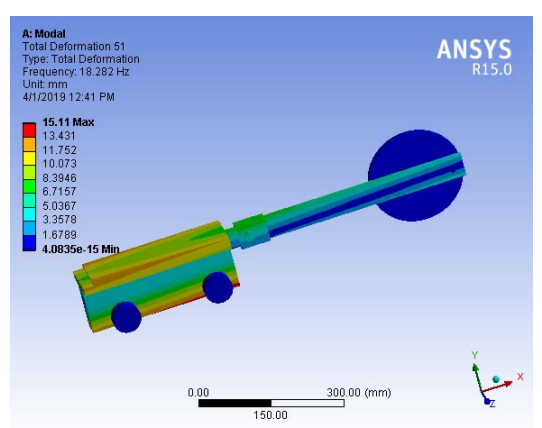

Figure 13. Modal frequency $(18.2 \mathrm{~Hz})$ and mode shape of trolley.

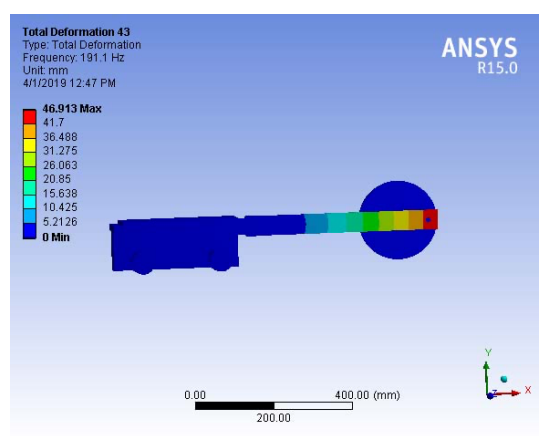

Figure 12. Modal frequency $(191.1 \mathrm{~Hz})$ and mode shape of connecting rod.

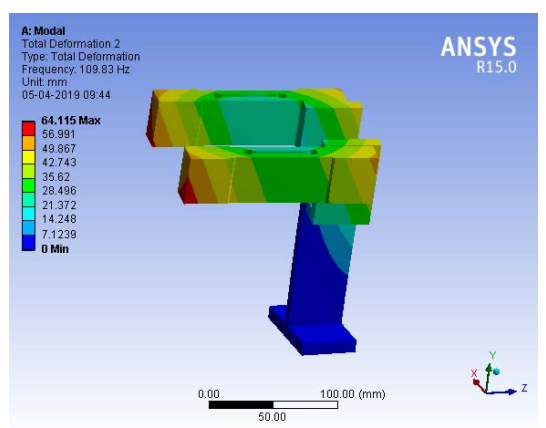

Figure 14. Modal frequency $(109.8 \mathrm{~Hz})$ and mode shape of load cells A and B.

\section{RESULTS AND DISCUSSION}

Table 1 gives the comparison between the modal frequency estimated through experimental and numerical routes.

Table 1. Estimated modal frequencies from Numerical and Experimental methods.

\begin{tabular}{|c|c|c|}
\hline Part name & $\begin{array}{c}\text { Modal frequency in } \mathrm{Hz} \\
\text { from experiments }\end{array}$ & $\begin{array}{c}\text { Modal frequency in } \mathrm{Hz} \\
\text { from Numerical analysis }\end{array}$ \\
\hline Loading arm & 28 & 31 \\
\hline Trolley & 18 & 181 \\
\hline Connecting rod & 128 & 109 \\
\hline Load cell A & 97 & 109 \\
\hline Load cell B & 97 & 191 \\
\hline
\end{tabular}




\subsection{Modal Frequency of Transmission System}

Fig. 4 provides the transmission system details. The whole system is not attached firmly. The countersurface is mounted on top of trolley. Here, the midpoint P3 on the countersurface mounted on trolley top had the maximum deflection. Trolley with counter surface attached on top is treated as a single unit or a rigid body. The direction of free vibration with maximum amplitude and lowest frequency was in the direction of reciprocation. Guides arrested other DoFs. The experimental value at point above the specimen holder was $18 \mathrm{~Hz}$ in experiments and $18.282 \mathrm{~Hz}$ in numerical experiments as Fig. 8. As per Plint (2011), 30\% of $18 \mathrm{~Hz}$, i.e., $5.4 \mathrm{~Hz}$, is approximated to $5 \mathrm{~Hz}$ fixed as the highest frequency of reciprocation. This was the lowest of all estimated modal frequencies. Hence, the maximum reciprocating frequency of the tribometer is fixed as $5 \mathrm{~Hz}$. If the trolley had vibrated in the reciprocating direction, it would have changed the stroke length in every cycle. The resonance could have induced large forces on the load cell and incorrect CoF values. Depending on the direction, it would have changed slid distance and wear loss. The second component with different DoF in transmission subsystem was the connecting rod. By limiting the reciprocating frequency, the vibration due to resonance of the trolley was avoided. The maximum deflection point was at P2 as in Fig. 4. Modal frequency of the connecting rod was estimated by experimental and numerical methods available in Tables 1 . The connecting rod is considered as a single rigid body. The experimental estimate of modal frequency at point P2 was $128 \mathrm{~Hz}$, and $191 \mathrm{~Hz}$ was the numerical value as in Fig. 12. This is larger than the lowest frequency estimated for trolley. Hence, the induced vibration on the connecting rod would not affect the CoF estimation up to $5 \mathrm{~Hz}$.

\subsection{Modal analysis of Loading Subsystem}

The details of loading system are elaborated in Fig. 3. The whole system consisted of parts attached firmly. Hence, each part is treated as a single unit or a rigid body. The direction of free vibration with maximum amplitude and lowest frequency was in the direction of reciprocation. The experimental value at point above the specimen holder was $28 \mathrm{~Hz}$ in experiments, and $31.431 \mathrm{~Hz}$ was the numerical value, which was higher than the $5 \mathrm{~Hz}$ trolley. The relevant graphs are Fig. 6 and Fig. 11.

\subsection{Modal Analysis of Measuring Subsystem}

Fig. 5 shows the details. This subsystem had two load cells firmly attached to the frame. The maximum deflection point on load cells due to excitation was in the direction of force. This deflection could have led to wrong reading of frictional force, as it was strain-gauge-based. The experimental value at the point $\mathrm{P} 4$ for load cell A and at point $\mathrm{P} 5$ was $97 \mathrm{~Hz}$ and $98 \mathrm{~Hz}$ in experiments, and $109.8 \mathrm{~Hz}$ was the numerical value. The relevant graphs are Fig. 9, Fig. 10, and Fig. 14. This frequency is larger than the maximum fixed frequency of reciprocation.

\subsection{Verification of Frequency Response of the Tribometer}

Confirmation experiments were performed on the reciprocating tribometer. The stroke length of reciprocation was kept constant at $100 \mathrm{~mm}$. Reciprocating frequencies were $1 \mathrm{~Hz}$ to $6 \mathrm{~Hz}$. The effective normal loads applied on the pin specimen were $30 \mathrm{~N}, 60 \mathrm{~N}$, and $90 \mathrm{~N}$, respectively. Using MATLAB, the signals were filtered with BESSEL filter. Fig. 15, Fig. 16, Fig. 17, Fig. 18, Fig. 19, and Fig. 20 show the plotted moving averages for two cycles of each trial. 


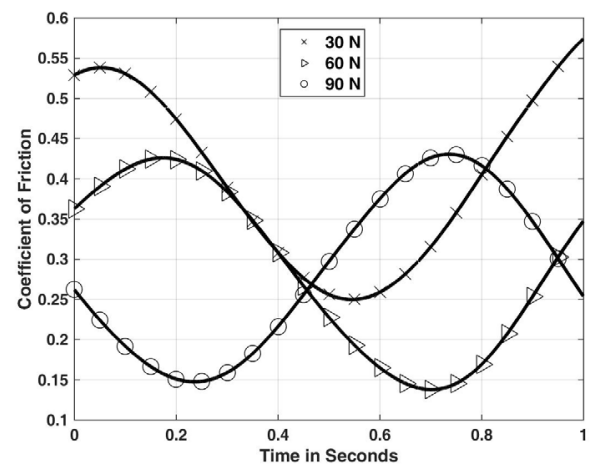

Figure 15. Two cycles of CoF Vs Time from load cell at $1 \mathrm{~Hz}$.

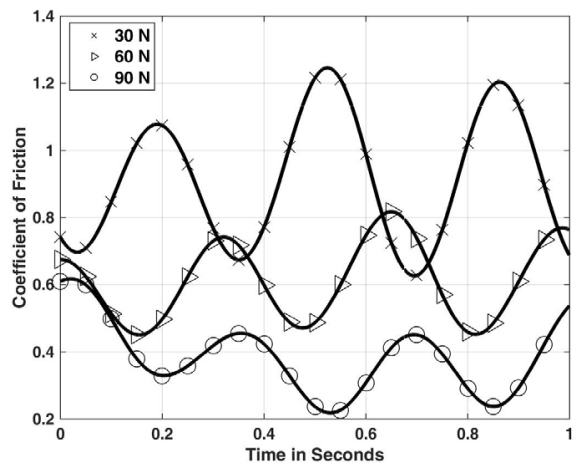

Figure 17. Three cycles of CoF Vs Time from load cell at $3 \mathrm{~Hz}$.

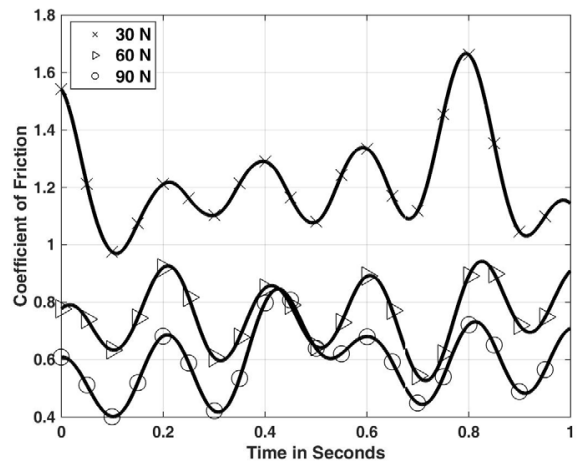

Figure 19. Two cycles of CoF Vs Time from load cell at $5 \mathrm{~Hz}$.

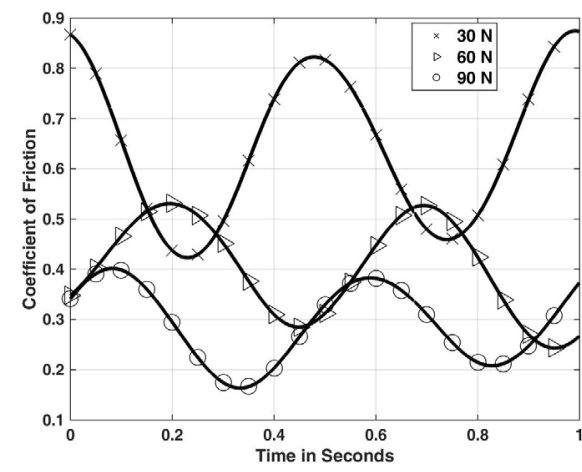

Figure 16. Two cycles of CoF Vs Time from load cell at $2 \mathrm{~Hz}$.

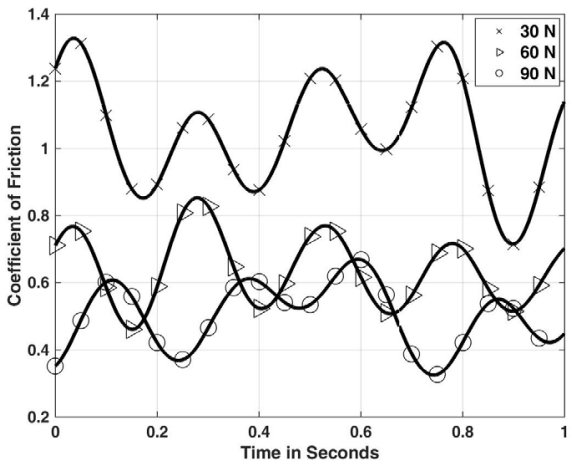

Figure 18. Two cycles of CoF Vs Time from load cell at $4 \mathrm{~Hz}$.

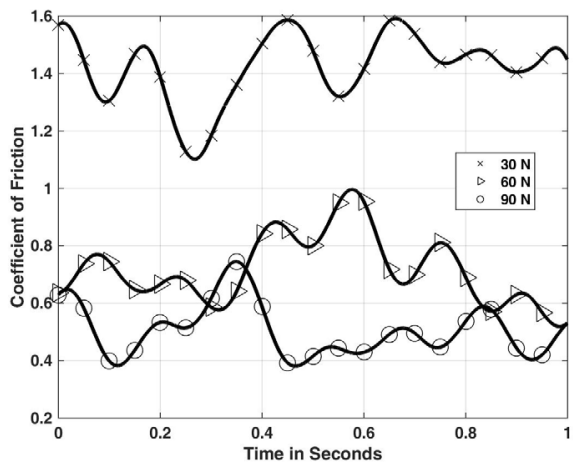

Figure 20. Two cycles of CoF Vs Time from load cell at $6 \mathrm{~Hz}$.

In Fig. 15, the frictional force for $30 \mathrm{~N}$ of normal load was lower compared to $60 \mathrm{~N}$ and $90 \mathrm{~N}$ of normal force. However, the peak at the middle of the stroke is distinguishable. The maximum frictional force was obtained from the peaks of the plots. The curve is sinusoidal as it is the response from one of two load cells on both sides. As the reciprocating frequency crosses the threshold frequency of $5 \mathrm{~Hz}$, the peaks are not distinguishable. This is in 
agreement with the paper of Plint (2011). The estimation of reciprocating frequency by experiment and numerical analysis is reliable as proved. Large noises in the readings of load cell were induced for $30 \mathrm{~N}$ of normal load and at frequencies above $4 \mathrm{~Hz}$. This can be explained as in Chowdhury and Helali (2006). Greater frictional force at higher frequency can be the result of reduced contact area due to the forced disengagement of contact surfaces by vibration. Some other reasons given in the paper were due to the instantaneous reduction of operative normal force. Other reasons are (i) superposition of static and dynamic force generated during vibration, (ii) reversal of the friction vector, (iii) local transformation of vibration energy into heat energy, and (iv) excitation frequency as high as resonance frequency (Chowdhury and Helali, 2006). As indicated in M Chen et al. (2007), the modal frequency of frictional contact changes due to the change in contact condition. At lower loads and higher frequencies (above $4 \mathrm{~Hz}$ and 30 $\mathrm{N}$ ), the rapid escalation of CoF may be due to this factor. The experiments in this paper support the argument in $\mathrm{M}$ Chen et al. (2007) that the estimation of change in natural frequency is necessary for the entire range of parameters to be tested.

\section{CONCLUSION}

Experimental and numerical modal testing of tribometer is performed. There are no standard modal testing procedures available for reciprocating tribometer (Ramalho and Celis, 2003). The present work provides a methodology of modal analysis of reciprocating tribometer. In this study, modal analysis of a tribometer was conducted on a subsystem level. The results obtained from the experimental and numerical analyses matched, which proves that the results are reliable. This study establishes the need for subsystem level modal analysis. The trolley heavy resonated at lower frequency $18 \mathrm{~Hz}$ and in the direction of reciprocation. Direction of vibration was in the direction of reciprocation and could have increased the lateral force in that direction. This could have resulted in higher frictional force and higher CoF than actual values. Considering the first effect in Plint (2011), the maximum reciprocating frequency can be fixed at $30 \%$ of lowest modal frequency of structure. However, at heavier loads and higher frequencies (above $30 \mathrm{~N}$ and $4 \mathrm{~Hz}$ ), the first effect in Plint (2011) gets dominance. Increased weight and velocity coupled with the reversals in direction at the end of every stroke transfer large momentum to the load cells. The slower decay time of previous cycle further causes the recovery of strained load cell. Hence, modal frequency of the reciprocating tribometer and the frequency at which the plucking effect (Plint, 2011) needs to be established as limiting reciprocating frequency for reliable results from reciprocating tribometer. In future, researchers will consider the methodology adopted in this work to conduct subsystem level modal analysis reciprocating tribometer. This will enable the future researchers to deduce the highest reciprocating frequency for reliable CoF estimation.

\section{ACKNOWLEDGMENT}

The authors are indebted to CERD of APJ Abdul Kalam Technological University, Kerala, India [https://ktu.edu.in/], for the financial assistance by Research Seed Money 2018 (KTU/RESEARCH/3/6727/2018 dated 16/01/2019) for this research work. The corresponding author is grateful to AICTE for QIP research fellowship. The vibration measurement and analysis were fully supported by the Advanced Dynamics and Control Lab, Department of Mechanical Engineering, College of Engineering, Trivandrum, India.

\section{REFERENCES}

Avitabile P. 2001. Experimental modal analysis. Sound and vibration, 35(1):20-31.

Bharat B. 2000. Modern Tribology Handbook, Vol. 1. CRC Press, 1 ed.

Blau P. 1989. Friction and Wear Transitions of Materials. Noyes Publications, Park Ridge, NJ. 
Blau P J. 1994. ASM Handbook Friction, Lubrication and Wear Technology, Vol. 18. ASM International, Materials Park, Ohio.

Blau P J. 2001. The significance and use of the friction coefficient. Tribology International, 34(9):585 - 591.

Brandt A. 2011. Noise and Vibration Analysis: Signal Analysis and Experimental Procedures. John Wiley \& Sons.

Brandt A. 2011. Noise and Vibration Analysis: Signal Analysis and Experimental Procedures. John Wiley \& Sons.

Chowdhury M A, Helali M M. 2006. The effect of frequency of vibration and humidity on the coefficient of friction. Tribology International, 39(9):958 - 962.

G133-02 A. 2002. Standard Test Method for Linearly Reciprocating Ball-on-Flat Sliding Wear. ASTM International.

Lee J, Lee B. 2012. Modal Analysis of Carbon Nanotubes and Nanocones using FEM. Computational Materials Science, 51(1):30 - 42.

M Chen, T Perry, AT Alpas. 2007. Ultra-mild wear in eutectic Al-Si alloys. Wear, 263(1 - 6) :552 - 561. 16th International Conference on Wear of Materials.

Plint G A. 2011. Friction force Measurements in Reciprocating Tribometers. (URL: http://www.phoenixtribology.com/wp-content/uploads/guidance/Guidance-Dynamic-Friction-Force.pdf)

Ramalho A, Celis P J. 2003. Fretting Laboratory Tests: Analysis of the Mechanical Response of Test Rigs. Tribology Letters, 14(3):187-196.

Schwarz B J, Richardson M H. 1999. Experimental modal analysis. CSI Reliability week, 35(1):1-12.

Stachowiak G, Batchelor A W. 2004. Experimental Methods in Tribology. Elsevier.

Unnikrishnan M, Rajan A, Basanthvihar Raghunathan B, Kochupillai J. 2017. Dynamic Testing of a Prestretched Flexible Tube for Identifying the Factors Affecting Modal Parameter Estimation. Journal of The Institution of Engineers (India): Series C, 98(4):421-430. 